\title{
Editorials
}

\section{The first 500 days: renewal, reform, reflection}

The post of chief medical officer for England has a broad range of responsibilities for health and health care at national level accounting to health ministers with an additional role as the United Kingdom's chief medical adviser. The present appointment was 15 th in a line of succession dating back to the middle of the 19 th century. Taking up post on the threshold of a new millennium made it a propitious moment when the past and future of health and health services were the subject of reflection and debate.

Strategically and day to day most of the work of the chief medical officer falls into four broad categories: improving the health of the population of England, ensuring high standards of care for patients in the National Health Service, protecting the public health, and addressing a wide range of clinical and scientific developments relevant to health and medicine. In addition, there is a major role in troubleshooting across a broad front that is unplanned and unpredictable as problems and crises arise.

Over the past two years all these areas have been characterised by fresh thinking, new developments, increased public and media interest and greater exchange of ideas internationally. The chief medical officer role has been at the centre of much of the change.

On the population health front, an important new white paper $^{1}$ set out a new and forceful commitment to improving health, reducing inequalities and tackling the major causes of mortality and premature death in England. The strengths of this new policy were its unambiguous pledge to reducing inequalities (which followed a special review of the subject ${ }^{2}$ ), the recognition that action would only be successful if it involved many other government departments (not just the health department), and the underlying philosophy of public health practice as multiprofessional, multiagency and evidence-based. Immediately preceding this inequalities driven white paper, the publication of a comprehensive strategy to combat tobacco was another seminal moment for public health in Britain.

Most recently, changes set out in the National Plan for the NHS $^{3}$ including a national inequalities target, the establishment of a health poverty index and the merger of the regional public health function of the NHS with the regional office of government, give added impetus to the implementation of these major public health strategies.

In Britain in the year 2001, consideration of health protection is inextricably linked to the way in which risk is assessed, controlled and communicated to the public. There is widespread acknowledgement that public trust in government and science more generally was badly dented by the bovine spongiform encephalopathy (BSE) crisis.

The involvement of the chief medical officer in tackling health risk concerns has been very large over the past two years in areas as diverse as: variant Creutzfeldt-Jakob disease (vCJD), ${ }^{4}$ mobile telephones, ${ }^{5}$ beef on the bone, ${ }^{67}$ genetically modified food, ${ }^{8}$ the total eclipse of the sun and measles, mumps and rubella vaccine.

Explaining the health risks to the public on these diverse issues has proved challenging. The language of risk is confusing to the public - words like "safe" or "unsafe" are no longer acceptable and phrases like "minimal risk", or "hypothetical risk" are not understood. There is constant confusion between "no evidence for an effect of . . . . .." and "no effect of .....". The mathematics of risk is also confusing for people. There is a need to think about the numerical as well as the qualitative side of conveying information to the public about risk and to be clear when distinguishing between absolute and relative risks.

Governments and their chief medical officers have a responsibility to make sure that the public is given understandable information about health risks and what those risks mean so that they are empowered to make informed choices. The approach to risk is changing leading to greater openness, earlier sharing of information on risk with the public and wider debate before risk interventions are taken.

In Saving lives: our healthier nation ${ }^{1}$ the British government set out for the first time a systematic approach to risk, founded on a set of guiding principles and key steps to be taken. The challenge now is to embed those guiding principles and key steps into routine practice.

Another important development in this respect was the establishment last year of an independent national Foods Standards Agency to give the public confidence that impartial and independent advice is being provided when there are possible risks to health from food.

A further major breakthrough in the health protection field was the launch of a conjugate vaccine against group $\mathrm{C}$ meningococcal infection. ${ }^{8}$ Britain was the first country to develop and introduce the vaccine against a disease that had caused a major public anxiety and hit the headlines over the past two winters. The programme, aimed at vaccinating 14 million children and young people over a 12 month period, had already saved lives by the six month point.

In the past three years there has been an unprecedented level of public concern about incidents within the NHS in which there have been serious failures in standards of care.$^{9-11}$ Although rare in proportion to the large volume of good health care delivered week in week out, such failures have threatened to undermine public confidence in the NHS as a whole. Concern has been heightened by the fact that the problems have come to light through the actions of patient groups and investigative journalists, not by the local NHS services recognising and dealing with them. This has encouraged the perception that the NHS in the past has been too willing to tolerate poor standards of care and local managers have been unwilling to challenge those doctors in powerful positions.

It has been the responsibility of the chief medical officer to support ministers by leading the production of new policies and their implementation to tackle these weaknesses in NHS procedures.

A statutory duty of quality has been introduced so that every local NHS organisation must have in place a system of clinical governance. ${ }^{12}$ New procedures have been introduced to deal with poor practitioner performance ${ }^{13}$ while a major report has addressed the longstanding problem of "medical error" and the importance of taking a systems approach to reduce risk and promote a safety culture. ${ }^{14}$

New national structures and processes have created a comprehensive quality framework to support local clinical governance. Over the past year, the National Institute for Clinical Excellence (NICE) and the National Service Frameworks have emerged as important components in 
the support structure for local clinical governance through setting evidence based standards. NICE has a key role in the appraisal of new technology (such as drugs and medical devices); for provision of guidance on the appropriate use of treatment interventions and procedures and for the development of clinical guidelines for the management of specific conditions.

National Service Frameworks (NSFs) are in place ${ }^{15} 16$ (and more are planned) to set national standards and define service models for specific patient groups. Each of the NSFs establishes performance measures against which progress will be measured. The standard setting mechanisms of NICE and the NSFs are reinforced by the work of another new body, the Commission for Health Improvement (CHI) that is beginning to inspect clinical governance arrangements and provide feedback to local NHS organisations to inform future development. In late 1999 a National Clinical Governance Support Team (NCGST) was established to support the development and implementation of clinical governance.

The task of thoroughly examining and advising government on the potential for major clinical development was most prominently discharged with the production of a report with recommendations that limited research into therapeutic cloning should be permitted. ${ }^{17}$ During my term so far there have been a number of unforeseen crises that have included the public outrage caused by the case of Dr Harold Shipman who was convicted of murdering 15 of his patients and the practice of retaining children's organs after postmortem examination without the full knowledge of the parents.

So the first 500 days for the new chief medical officer for England, have been a period of unprecedented change but a time in which the climate has been right for radical reform. A positive set of policies are now in place to tackle major and longstanding health problems and inequalities backed from the very top of government. A systematic approach is being taken to improving quality and reducing tolerance of poor standards of care. A new strategy is being adopted for addressing and communicating risk so as to restore trust in public health and scientific advice. Rigorous examination continues to take place to assess the benefits and drawbacks of major clinical developments as they present themselves. A number of health crises and medical scandals have provided the opportunity for a fundamental re-examination of the relationship between patient, health care professional and service.

The task is now to ensure successful implementation in this favourable policy environment. That is the key challenge of the next 500 days.

\section{LIAM J DONALDSON}

Chief Medical Officer

Department of Health, Rm 111 Richmond House, 79 Whitehall, London

SW1A2NS (Liam.Donaldson@doh.gsi.gov.uk)

1 Department of Health. Saving lives: our healthier nation. London: The Stationery Office, 1999 (Cm 4386).

2 Acheson D. Report of the Independent Inquiry into Inequalities in Health. Acheson D. Report of the Independent

3 Secretary of State for Health. The NHS plan: a plan for investment, a plan for reform. London: The Stationery Office, 2000 (Cm 4818-I)

4 Andrews NJ, Farrington CP, Cousens SN, et al. Incidence of variant Creutzfeldt-Jakob disease in the UK. Lancet 2000;356:481-2.

5 Independent Expert Group on Mobile Phones. Mobile phones and health. Didcot: National Radiological Protection Board, 2000.

6 Donaldson L. Bone-in beef and cattle bones: advice to the government from the chief medical officer. July 1999. www.doh.gov.uk//cmo/beef.htm

7 Donaldson L, May R. Health implications of genetically modified foods. May 1999. www.doh.gov.uk/gmfood.htm

8 Department of Health. Start of the new meningococcal $C$ conjugate vaccine immunisation programme. London: Department of Health, 1999 (professional letter: PL/CMO/99/4, PL/CNO/99/8, PL/CPHO/99/3).

9 Smith R. Regulation of doctors and the Bristol inquiry. Both need to be credible to both the public and doctors. BMF 1998;317:1539-40.

10 Dyer C. Obstetrician accused of committing a series of surgical blunders. BM7 1998;317:767.

11 Beecham L. Milburn sets up inquiry into Shipman case. BMf 2000;320: 401

12 Donaldson LJ. Clinical governance: a new statutory duty for quality improvement. F Epidemiol Community Health 1998;52:73-4.

13 Department of Health. Supporting doctors, protecting patients. London: Department of Health, 1999

14 Department of Health. An organisation with a memory: report of an expert group on learning from adverse events in the NHS. London: The Stationery Office, 2000.

15 Department of Health. National service framework for mental health: modern standards and service models for mental health. London: Department of Health, 1999.

16 Department of Health. National service framework for coronary heart disease. London: Department of Health, 2000.

17 Department of Health. Stem cell research: medical progress with responsibility. London: Department of Health, 2000. 